\title{
Tegumentary Leishmaniasis in Childhood
}

\author{
Achiléa L. Bittencourt,* Aldina Barral,* and Jackson M. L. Costa \\ *Department of Pathology and Immunology, School of Medicine, Federal University of Bahia, Brazil, \\ and the tDepartment of Infectious and Parasitic Diseases, School of Medicine. Federal University of \\ Maranhão, Brazil
}

\begin{abstract}
Very little has been published about tegumentary leishmaniasis in children and there are many controversies about this disorder in the literature. Therefore, we discuss the pathogenesis, clinical aspects, means to diagnosis, and treatment of this endemic disease.
\end{abstract}

Leishmaniasis is an endemic infection that occurs predominantely in tropical and subtropical regions of the world. There are an estimated $400 \mathrm{mil}$ lion individuals exposed to leishmanial infection and 600,000 new cases per year (1). Cutaneous leishmaniasis and its mucosal involvement represent a major health problem in South and Central America, where disfiguring mucosal involvement can occur in children.

Tegumentary leishmaniasis has a wide spectrum of clinical manifestations varying from the responsive-localized cutaneous and mucosal leishmaniasis (CL and MCL)-to the unresponsive-diffuse cutaneous leishmaniasis (DCL). Intermediate forms of this disease are also observed. The main differences between the polar forms of leishmaniasis are shown in Table 1. This spectrum is dependent on the species of leishmania and on the efficiency of the cell-mediated immune (CMI) response to the parasite. Post-kala-azar dermal leishmaniasis (PKDL), which represents the involvement of the skin after treatment of visceral leishmaniasis (VL), is caused by viscerotropic species of leishmania ( $L$. donovani and L. chagasi) (2).

The parasites that cause tegumentary leishmani-

Address correspondence to Achiléa L. Bittencourl, Serviço de Anatomia Patológica, Hospital Universitário Prof. Edgard Santos, Rua João das Bostas, s/n, Cancla, 40.110-060 SalvadorBahia-Brazil.

This article was supported by the Brazilian National Research Council (CNPq) and United States Public Health Service grant Al30639. asis are grouped under the $L$. braziliensis and $L$. mexicana complexes. Parasites of the $L$. braziliensis complex generally cause $\mathrm{CL}$ and $\mathrm{MCL}$, whereas parasites of the $L$. mexicana complex generally do not involve the mucosae and cause only limited selfhealing cutaneous lesions. The majority of the cases of MCL in the New World arc caused by $L$. brasiliensis. However, MCL may also be caused by $L$. panamensis and $L$. amazonensis (2). On the other hand, $C L$ is a rare sequela of infection with $L$. chagasi, the agent of New World VL (3). L. mexicana and $L$. amazonensis are responsible for the rare cases of DCL (4).

$L$. tropica, L. aethiopica, and L. major are the etiologic agents of Old World CL. However, $L$. tropica may also cause VL, and L. aethiopica is responsible for Oriental DCL. The disease caused by $L$. major" constitutes the rural "wet" form of Old World $\mathrm{CL} ; L$. tropica is responsible for the urban "dry" form of CL. However, the differences between these two types of disease are not always observed. "Dry" lesions may be caused by $L$. major, and $L$. tropica may occur as a rural disease (2).

A prospective study of $\mathrm{CL}$ in an endemic rural area (Corte de Pedra) of Bahia, a state in northeast 
TABLE 1. Main Differences Among Disseminated Cutaneous Leishmaniasis, Diffuse Cutaneous Leishmaniasis, and Classical American Cutaneous Leishmaniasis

Clinical and Immunopathologic

Findings

Clinical presentation

Number of lesions

Destructive mucosal involvement

Tissue parasitism

Follicular pattern

Granulomatous pattern

Antileishmanial CMI in vitro and in vivo

Antihody titers
Clinical Forms of Leishmaniasis

\begin{tabular}{lll}
\hline Disseminated & DCL & CL and MCL \\
$\begin{array}{lll}\text { Papules and acneiform } \\
\text { lesions }\end{array}$ & Nodules & Ulcers \\
Many & Many & One or few \\
Frequent & Absent & Infrequent \\
Rare or absent & Abundant & Rare or absent \\
Present & Absent & Absent \\
Present or absent & Absent & Present or absent \\
Positive or negative & Negative & Positive \\
Mainly high & High & Low
\end{tabular}

Brazil, allowed us to observe early manifestations of the disease and cases with spontancous healing. In this area most of the cases are due to $L$. braziliensis. In 2076 cases of cutaneous leishmaniasis, $35 \%$ were children 15 years old or younger $157 \%$ male and $43 \%$ female); $1.6 \%$ of these children presented with mucosal involvement. Figure 1 shows the frequency of $\mathrm{CL}$ in different age groups.

Cutaneous leishmaniasis caused by $L$. venezuelensis affects children less than 6 years of age in $19 \%$ of the cases (5). In Saudi Arabia. $66 \%$ of the patients with CL were younger than 10 years of age (6), and $L$. aethiopica occurs in the age group of 0 to 10 years in $37 \%$ of the cases $(7)$. DCL begins in childhood in approximately $66 \%$ of the cases in the Old World and in $61 \%$ of the cases in the New World (8-24).

\section{PATHOGENESIS}

Following inoculation in the skin, the flagellated promastigotes are transformed into amastigotes inside the macrophages, where they replicate within vacuoles. Leishmanicidal activity is probably due to the increased capacity of the macrophages to produce toxic oxygen and nitrogen radicals in re-

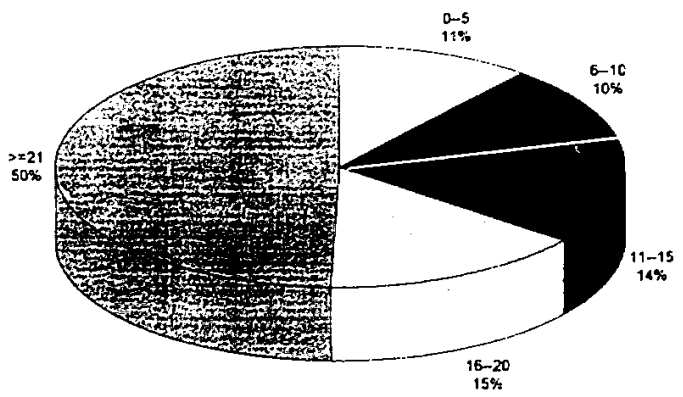

Figure 1. Age distribution (years) of 2,076 cases of cutaneous leishmaniasis of an endemic area of Bahia, Brazil. sponse to IFN- $\gamma(2)$. Upon entry leishmania induces the macrophage production of $\mathrm{TNF}^{-}-\alpha$. which potentiates the action of IFN- $\gamma$ and promotes macrophage activation (25), and TGF- $\beta$ (26), which is linked to macrophage deactivation and inhibition of IFN- $\gamma$ (27.28). Initial survival of leishmania inside the macrophage may depend critically on which of these opposing cytokines predominate in the microenvironment of infection.

Some observers suggest a role for Langerhans cells and keratinocytes in the modulation of CMI in leishmaniasis. Hyperplasia of Langerhans cells has been observed in human CL lesions (2). Also, these cells transport leishmania to the draining lymph nodes and induce an antigen-specific $T$ cell response (29).

In several immunologically mediated skin diseases, MHC class II-positive keratinocytes are observed to be associated with IFN-y production by surrounding $T$ cells. These cells appear to be able to produce cytokines and maintain clonal expansion of activated lymphocytes. MHC class II-positive keratinocytes have been observed in CL but not in DCL lesions. This finding suggests that there is a lower IFN- $\gamma$ production in DCL lesions. Epithelial hyperplasia is observed in CL and MCL, but not in DCL, and allows an increased contact between keratinocytes and inflammatory cells. This phenomenon is also considered to be related to IFN- $\gamma$ production. These aspects, together with the observation of an epidermotropism of $\mathrm{T}$ lymphocytes in $\mathrm{CL}$ and $\mathrm{MCL}$ lesions, suggest a role for Langerhans cells and keratinocytes in the modulation of $\mathrm{CMI}$ in $\mathrm{CL}$ and MCL (2).

\section{CLINICAL ASPECTS}

In New World CL, the most frequent lesion is an ulcer with an elevated border and sharp crater. The disease may also manifest as papules, nodules, tu- 
bercles or infiltrated plaques, diffuse infiltration (Fig. 2), and less frequently as verrucous lesions or vegetations. Multiple lesions occur in one-third of patients (2). In Brazil the lesions are generally located on the lower limbs, but in children they are more frequently situated on the head $(67.6 \%)$ and upper limbs (26\%) (30). Irrespective of the age, $L$. mexicana involves the external ear in $40 \%$ to $93 \%$ of patients and sometimes causes destruction and mutilation (4); and $51 \%$ of the lesions caused by $L$. venezuelensis are located on the face (5).

Mucosal lesions develop from the primary lesion by hematogenous spread and occur a few weeks to many years after the onset of infection. Usually the lesion begins in the nasal mucosa, but it can spread to the hard and soft palate, uvula, pharynx. gums, and upper lips. In cases of longer evolution the infiltration can cause enlargement of the upper lip and nose, conferring a tumoral appearance (Fig. 3). Nasal septal perforation is observed in many patients. Involvement of the larynx and vocal cords causes hoarseness and sometimes dysphonia. Mucosal involvement is most frequently caused by $L$. brasiliensis (2). Rarely MCL caused by L. tropica has been described in children (31). Retrospective studies have shown that the risk for mucosal disease is associated with inadequate treatment and multiple lesions above the waist.

The cutaneous lesions of Old World leishmaniasis heal spontaneously in $90 \%$ to $95 \%$ of patients. The lesions caused by L. tropica appear as single or multiple sofi red papules that develop a central serous crust (dry type). The lesions caused by L. major are larger, 2 to $5 \mathrm{~cm}$ in diameter, and generally develop a central necrosis that produces a hemorrhagic crust. These are multiple lesions in $80 \%$ of cases (31). L. aethiopica causes a single, reddish

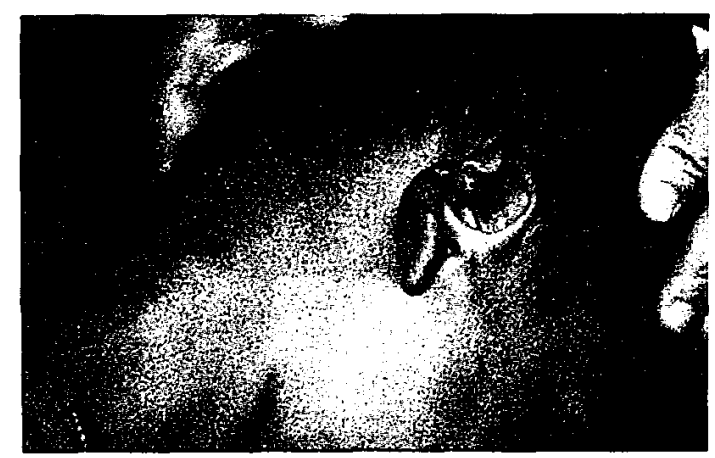

Figure 2. Diffuse infiltration and deformation of the ear in an 11-year-old child, a rare lesion of leishmaniasis caused by $L$. braziliensis. Note the regional lymphadenopathy.

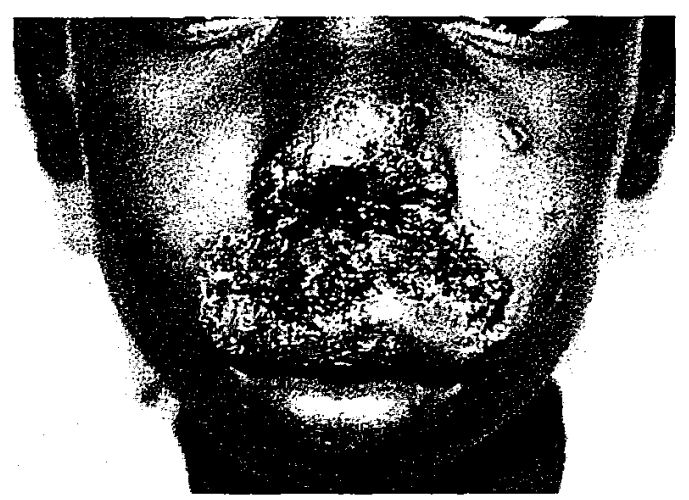

Figure 3. An intense infiltration of the nose and upper lip with destruction of the nasal septum.

plaque, 2 to $6 \mathrm{~cm}$ in diameter, with a shallow ulcer in the center and papular elements locally (7).

Besides the classic aspects of $\mathrm{CL}$, other forms of tegumentary lcishmaniasis can be observed in children including recidiva cutis, disseminated, sporotrichoid, and lymphonodal leishmaniases.

Leishmaniasis recidiva cutis or lupoid lcishmaniasis is characterized by the appearance of active lesions around leishmanial scars or by peripheral spreading of the lesion with central healing (Fig. 4). It has been described as a manifestation of both Old and New World leishmaniases. The lesions have an indolent course and are resistant to treatment (32).

Disseminated leishmaniasis is due to the hematogenous dissemination of parasites. and many lesions can be observed simultancously. The lesions appear as acneiform, small papules that sometimes transform into small ulcers. This form of disease is completely different from DCL (Table 1), an entity that also presents with many lesions that are nodular and nonulcerated $(33,34)$.

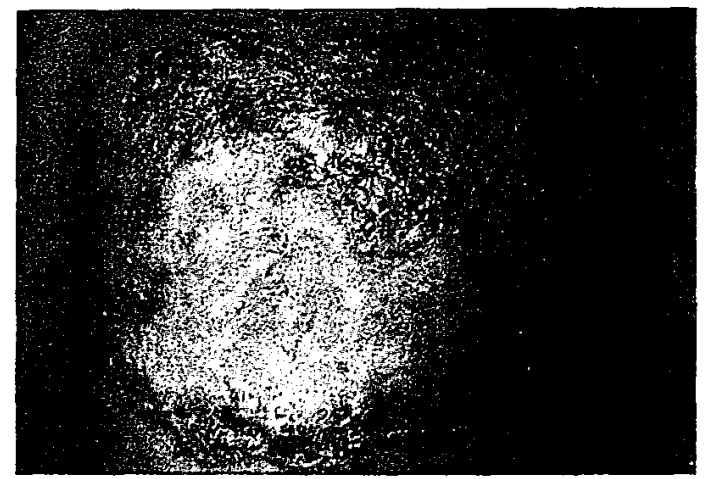

Figure 4. A 2-year-old child with an extensive scar and active lesions at the periphery caused by $L$. braziliensis. 
The lymphatic form of $\mathrm{Cl}$, with a sequence of nodules along the lymphatic draining route, may mimic sporotrichosis. In the New World, lymphatic CL has been caused by L. braziliensis, L. guyanensis, and L. panamensis (2).

Regional lymphadenopathy with early resolution is a common aspect of New World CL (lymphonodal form of $\mathrm{CL}$ ), especially in the infection caused by $L$. braziliensis. This presentation of $C L$ is frequent in childhood. In 36 patients with $\mathrm{CL}$ with lymph node enlargement, $44 \%$ were patients less than 16 years of age. Patients with lymphadenopathy had higher antileishmanial CMI responses as well as humoral antibody responses (35). In some cases of CL caused by $L$. braziliensis, lymphadenopathy represents the first sign of disease and sometimes the only manifestation of infection (35). In CL caused by $L$. major, $10 \%$ of the patients have lymph node enlargement (36).

Diffuse CL presents with widespread erythematous nodules and infiltrated plaques (Fig. 5). Between the polar forms of tegumentary Ieishmaniasis, a borderline or intermediate disease has been rarely reported $(8,37,38)$. Recently, cases of an intermediate form of DCL situated in the spectrum between the classic DCL and the borderline form have been described, some of them heginning in infancy (38).

Post-kala-azar dermal leishmaniasis (PKDL) occurs in about $20 \%$ of VL cases 1 to 5 years after the clinical cure of the disease, but it can appear during

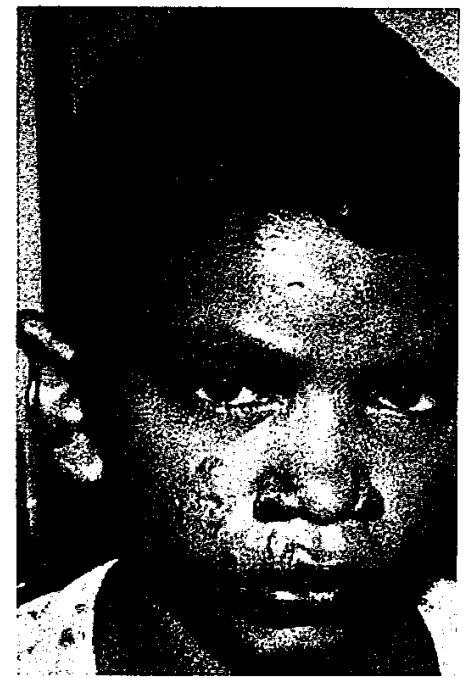

Figure 5. Diffuse leishmaniasis. A 12-year-old boy with infiltrated lesions on the face and ears simulating lepromatous leprosy. or shortly after treatment (39). It occurs as multiple hypochromic macules that develop into nodules. Usually an erythematous macular eruption on the cheeks is the first manifestation of the disease.

\section{IMMUNE RESPONSE}

The immune response in tegumentary leishmaniasis is characterized by the important role of the CMI response. The humoral immune response induces the production of specific antibodies. There is suppression of the CMI in DCL and in borderline leishmaniasis (the anergic pole) as demonstrated by the absence of a delayed type of hypersensitivity (DTH) response in vivo in the Montenegro reaction (leishmania skin test), defective lymphocyte proliferative response in vitro, and decreased IFN- $\gamma$ and IL-2 production. The defective response in vitro is observed when the peripheral blood mononuclear cells of DCL patients are cultivated with leishmania antigen. However, there is a good response to other antigens, such as PPD and candida, and lectins, such as phytohemoaglutinin or concavalin $A$. In active MCL the intradermal skin test and lymphocyte proliferative responses are strong and lymphocytes from these patients can produce IFN- $\gamma$, which inhibits intracellular replication of leishmania (40). Mucosal CL may represent a hypersensitivity state to leishmania.

The humoral immune response in the $\mathrm{DCL}$ patients shows a high production of specific antibodies in titcrs that range from $1 / 124$ to $1 / 16,000$ as detected by an immunofluorescent assay using intact promastigotes (38).

\section{PATHOLOGY}

At the initial stages of human infection, there is an accumulation of polymorphonuclear neutrophils and to a lesser degree eosinophils. These cells are gradually replaced by a monotonous infiltration of vacuolated and parasitized macrophages (macrophagic phase). The lesions of Old World CL remain in this phase longer than those of New World CL (2).

In New World $\mathrm{CL}$ and $\mathrm{MCL}$, the inflammatory infiltrate is generally diffuse and consists of plasma cells (the predominant cells), macrophages, and lymphocytes. It is frequently associated with a granulomatous reaction represented by scattered giant and epithelioid cells. These cells are disposed in a disorganized pattern and may be associated with caseous necrosis (Fig. 6). Well-organized granulomas may also be observed (Fig. 7). The frequency 


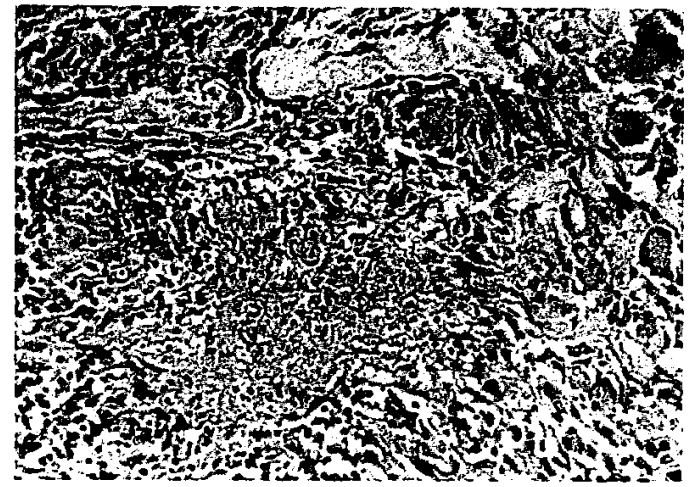

Figure 6. Cutaneous leishmaniasis. Caseous necrosis surrounded by giant cells. (Hematoxylin and eosin: magnification $160 \times$.)

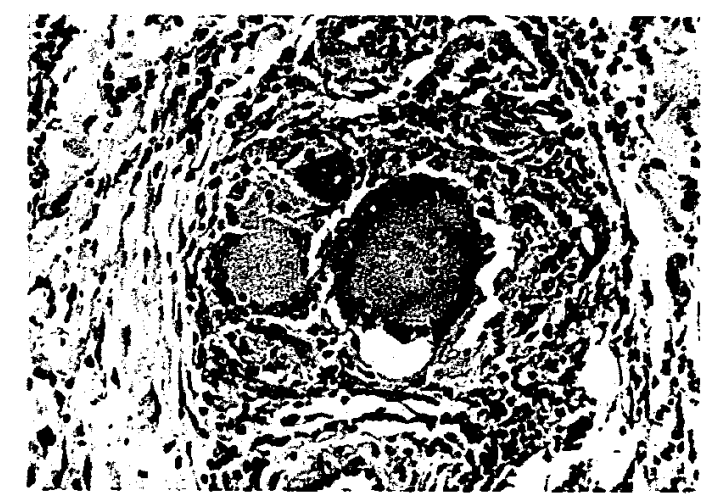

Figure 7. Cutaneous leishmaniasis. A well-organized granuloma with giant and epithelioid cells. (Hematoxylin and eosin; magnification $64 x$.)

of granulomatous reactions in $\mathrm{CL}$ and $\mathrm{MCL}$ varies from $50 \%$ to $82 \%$ depending on the number of biopsy specimens examined from a single patient. In American $\mathrm{CL}$ granulomatous reactions may be observed in lesions that have evolved in only a few weeks (2).

In lesions of New World CL and MCL, the parasites are generally scarce or absent. They are more frequent in recent lesions. Amastigotes are more numerous in the lesions of Old World CL, especially in the "dry" type of disease (2).

The necrosis observed in New World CL is generally caseous and simulates cutaneous tuberculosis. However, this type of necrosis is not observed in Old World CL and cytolytic necrosis is frequently reported (41). Cytolytic necrosis results from macrophagic disruption in lesions with a parasite index between 2 and 4 (between 100 and 10,000 parasites per standard section). It is usually associ- ated with an infiltration of neutrophils-many are in karyorrhexis. In Brazilian $\mathrm{CL}$, this type of necrosis is only seen in cases of CL with areas of marked parasitism or in DCL during treatment (2).

New World CL and MCL present with varied histopathologic findings in different lesions of a single patient and sometimes within the same lesion. For this reason classifications of $\mathrm{CL}$ and $\mathrm{MCL}$ based on histopathologic characteristics have no value (42).

In New World CL and MCL the surface epithelium is generally hyperplastic, assuming a pseudocarcinomatous appearance with deep downgrowths infiltrating the dermis or the corium. Intraepidermal abscesses, epidermotropism, and spongiosis are also frequently seen in the epidermis and represent transepidermal elimination of the dermal infiltrates as described in subcutaneous mycoses. Epidermal hyperplasia is less frequently observed in Old World leishmaniasis (2). In lymph nodes, a granulomatous reaction with caseous necrosis may be observed and sometimes is associated with parasitism (2).

Microscopically, DCL consists of a monotonous infiltrate of vacuolated and heavily parasitized macrophages that replace the dermis and sometimes the hypodermis. This macrophagic aspect is frequently associated with epidermal atrophy. In borderline leishmaniasis there is an association of the macrophagic aspect with a granulomatous reaction (2).

\section{HISTOPATHOLOGIC DIFFERENTIAL DIAGNOSIS}

In patients with parasitism a differential diagnosis must be made with histoplasmosis. Although Histoplasma capsulanum lacks the kinetoplast, it may often resemble amastigotes. However, with the Gomori methenamine silver stain, the budding forms of the fungus can be easily visualized. Additionally, an identification in situ of leishmania using antiamastigote antibodies can confirm the diagnosis of leishmaniasis.

Histologically cases of $\mathrm{CL}$ with a granulomatous reaction and microabscesses may mimic sporotrichosis, a mycotic disease where fungal forms are difficult to find. The diagnosis can be made isolating Sporothrix schencki by culture. In addition, positive results of serology, culture, and skin testing for leishmaniasis may provide the correct diagnosis of leishmaniasis.

In cases where a granulomatous reaction with caseous necrosis exists and amastigotes are not demonstrated histopathologically, the differential 
diagnosis must include tuberculosis. As acidalcohol resistant bacilli are not commonly found in cutaneous tuberculosis, it is mandatory to culture the lesion, perform skin testing for both etiologic agents, and conduct serologic tests for leishmaniasis.

Diffuse cutaneous leishmaniasis must be differentiated from PKDL because both conditions may present with nodules and a large number of amastigotes. For histopathologic diagnosis, it is necessary to take into account the presence of hypochromic macules (observed only in PKDL) and the clinical history.

\section{LABORATORY DIAGNOSIS}

The diagnosis is made by direct examination of smears, histopathology, serologic lests, and skin testing with leishmanin (Montenegro reaction). Direct observation of parasites can be made in Giemsa-stained smears of aspirate specimens, superficial scrapings of the ulcers, or imprints of biopsy specimens. The amastigotes are oval or round and 2 to $3 \mu \mathrm{m}$ in length. Giemsa-stained preparations of amastigotes show a pale blue cytoplasm with two eosinophilic-stained structures-a round nucleus and a rod-shaped kinetoplast (Fig. 8). Considering the scarcity of parasites in lesions of $\mathrm{New}$ World CL and MCL, it is recommended to search for leishmania in more than one stained smear. The biopsy material or aspirates may also be used for culture and animal inoculation. Indirect immunofluorescence assay and EILISA are the most commonly used serologic techniques, and they demon-

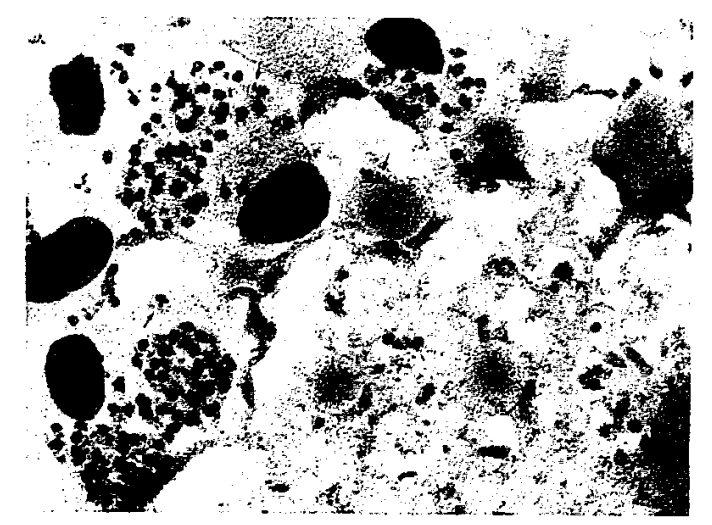

Figure 8. Diffuse cutaneous leishmaniasis (a smear of aspirate specimen). Many amastigotes lie free or within macrophages. Observe the round nucleus and the kinetoplast of amastigotes (arrows). (Giemsa stain; magnification $1200 \times$.) strate a good sensitivity and specificity. The Montenegro skin test is positive in only $51.6 \%$ of cases of $L$. amazonensis infection, whereas a positivity of $87 \%$ is observed in infections with other species of leishmania (2). When no parasitologic evidence of infection is demonstrated, diagnosis can be made using the polymerase chain reaction (PCR), which is much more sensitive than the conventional parasitologic methods and also enables identification of the species of leishmania $(43,44)$.

The diagnosis of DCL and borderline leishmaniasis can be made through smears or histopathology because the lesions are rich in parasites. In both DCL and borderline leishmaniasis, the Montenegro test is negative. but serology is positive, exhibiting higher titers in DCL than those observed in CL (2).

In all forms of leishmaniasis it is important to obtain the species characterization of the parasite. Characterization in situ can be performed by immunocytochemistry using appropriate monoclonal antibodies in sections of paraffin-embedded tissue (45).

\section{TREATMENT}

Pentavalent antimony is the drug of choice for the treatment of $\mathrm{CL}$ and $\mathrm{MCL}$ in childhood. However, it sometimes requires repeated doses, and side effects are frequent. Sodium stibogluconate (Pentostam $^{\sharp}$ ) or meglumine antimoniate (Glucantime ${ }^{\natural}$ ) are drugs administered by intramuscular or intravenous routes. The mechanism of action is through interference with the ATP synthesis of the parasites (46). The side effects are cumulative and dose dependent. Antimony can affect the organs in the following order of frequency: heant, kidney, liver, and brain. The single dose toxic limit for man is about 30 $\mathrm{mg} / \mathrm{Sb}^{\gamma} / \mathrm{kg}$ (47). The more frequent side effects are musculoskeletal pain, anorexia, elevation of hepatocellular enzyme levels. alterations of the electrocardiogram ( $T$ wave flattening and/or inversion), and renal dysfunction $(46,47)$.

Systemic treatment for $\mathrm{CL}$ is also indicated to prevent mucosal involvement, especially in the infections caused by the $L$. braziliensis species complex (47). For the intravenous route, dilution is not necessary and the administration should be done slowly with a fine needle over 5 minutes.

The recommended dose for CL is 10 to $20 \mathrm{mg} /$ $\mathrm{Sb}^{2} / \mathrm{kg} /$ day for 20 consecutive days, but this dose may vary according to the morphology and frequency of the lesions and the clinical response $(46,47)$. For simple skin ulcers caused by $L$. braziliensis, $10 \mathrm{mg} / \mathrm{Sb}^{\mathrm{v}} / \mathrm{kg} /$ day for 20 days continuous 
treatment is the recommended schedule. For MCL, a dose of $20 \mathrm{mg} / \mathrm{Sb}^{\%} / \mathrm{kg} / \mathrm{day}$ is recommended for 30 days or more depending on the clinical response (47). The treatment of DCL with pentavalent antimony is not curative. In the initial phase of treatment some clearing of the lesions may be observed, but relapses always occur (48).

The treatment of $\mathrm{Cl}$ must be maintained until complete clinical and parasitologic cure is achieved. Patients should be reevaluated 4 to 6 weeks after therapy. If the lesions do not regress, continuation of treatment with the same schedule should be considered. Pentavalent antimonials should not be used in children with cardiopathy, nephropathy, or hepatic disease.

Amphotericin B and pentamidine are used as second-line therapy in patients who do not respond to the antimonials. These drugs are potentially toxic and require intramuscular or intravenous administration. Amphotericin B is more often used in MCL. but a few cases relapse after this therapy (47). The recommended dose is 0.5 to $1.0 \mathrm{mg} / \mathrm{kg} / \mathrm{day}$ up to a total dose of 20 to $30 \mathrm{mg} / \mathrm{kg}$ (46), but some patients have been cured with lower doses $(46,47)$. The recommended dose of pentamidine is $2 \mathrm{mg} / \mathrm{kg}$ on alternate days for a period of 1 week for cutaneous lesions or 5 weeks for MCL and DCl. These drugs are not recommended for children with diabetes and renal, hepatic, or cardiac diseases (49).

A great number of drugs have also been $\mathrm{cm}$ ployed for the treatment of tegumentary leishmaniasis. Systemic therapy with furazolidone. aminosidinc, allopurinol, nifurtimox, and others have been tried. with variable results. Many of these drugs need only oral administration which simplifies the treatment $(46,50)$. In limited forms of leishmaniasis intralesional glucantime has been used with partial or complete clearing of lesions $(51,52)$. The aminoglycoside paramomycin has been tried as an ointment at $16 \%$ with $12 \%$ methylbenzethonium chloride in Oriental and American leishmaniasis with favorable results $(53,54)$. However, Asilian et al (55), using an ointment containing 15\% aminosidine and $10 \%$ urea in petrolatum in a 2 -weck regimen did not observe clearing of the lesions. Other local therapy like cryosurgery, localized controlled heat, and carbon dioxide laser alone or associated with systemic drugs have been attempted in some cases (46, $56,57)$.

The use of cytokines, which stimulate leishmanicidal macrophage activity, has also been tried in antimony-resistant cases. A recent study reports complete clearing of lesions in two patients with antimony-resistant DCL after combined systemic administration of IFN- $y$ and pentavalent antimony (58).

The criteria of cure are the clinical clearing of lesions along with the absence of or a marked drop in serologic titers. An effective and early treatment of $C L$ is mandatory mainly in areas where $L$. braziliensis is the predominant agent in order to avoid mucosal involvement (47).

\section{REFERENCES}

I. Modabber F. The leishmaniases. In: Maurice J, Pearce AM. eds. Tropical diseases research, a global partnership. Eight Programme Report. TDR. Geneva: World Health Organization. 1987:99-112.

2. Bittencourt A. Barral-Netto M. Leishmaniasis. In: Doerr W. Seifert G. Tropical pathology. Heidelberg: Springer. 1995:597-651.

3. Barral A. Pedral-Sampaio D, Grimaldi G Jr, Momen H, McMahon-Prati D, Jesus AR, Almeida R, Badaró R. Barral-Netto $M$, Carvalho EM, Johnson WD $J_{r}$. Leishmaniasis in Bahia-Brazil: evidence that $L$. amazonensis produces a wide spectrum of clinical disease. Am J Trop Med Hyg 1991:44:536-546.

4. Grimaldi G Jr. Tesh R. McMahon-Pratt D. A review of the geographic distribution and epidemiology of leishmaniasis in the New World. Am J Trop Med Hyg 1989:41:88-400.

5. Bonfante-Garrido R, Meléndez E, Barroeta S, Alejos MA. Momen H. Cupolillo E, McMahon-Pratt D. Grimaldi $G J_{r}$. Cutaneous leishmaniasis in western Venezuela caused by infection with $L$. veneauelensis and $L$. braziliensis variants. Trans $\mathrm{R}$ Soc Trop Med Hyg 1992:86:141-148.

6. Al-Gindan Y, Ahdul-Azia O, Kubba R. Cutaneous leishmaniasis in Al-Hassa. Saudi Arabia. Int J Dermatol 1984;23:194-197.

7. Mengistu G. Laskay T, Gemetchu T. Humber D, Ersamo $M$. Evans D. Teferedegn $H$, Phelouzat MA, Frommel D. Cutaneous leishmaniasis in southwestern Ethiopia: Ocholo revisited. Trans R Soc Trop Med Hyg 1992;86: 149-153

8. Bryceson A. Diffuse cutaneous leishmaniasis in Ethiopia. I. The clinical and histological features of the disease. Trans Roy Soc Trop Med Hyg 1969;63:708739.

9. Barrientos L. Um caso atípico de leishmaniose cutáneo-mucosa. Mem Inst Oswaldo Cruz 1948;46: $415-418$.

10. Convit J. Kerdel-Vegas F. Gordon B. Disseminated anergic cutaneous leishmaniasis. Brit $J$ Dermatol 1974;74:132-135.

11. Diaz H, Martinez. Quiñones M, Estevez F. Leishmaniose anérgica na Republica Dominicana. Estudo de 20 casos. An Bras Dermatol 1985:60(suppl. 1): 229-236.

12. Fonseca A. Araújo R. Fonseca W. Leishmaniose tegumentar difusa. Med Cut ILA 1981;IX:317-322.

13. Balzer R, Destombes P, Schaller K, Serie C. Leish- 
maniose cutaneé pseudolepromateuse on Ethiopie Bull Soc Path Exot 1960;53:293-298.

14. Franke E, Lucas C, Tovar A, Kruger H, Rivera VS, Wignall FS. Diffuse cutaneous leishmaniasis acquired in Peru. Am J Trop Med Hyg 1990;43:260-262.

15. Marquez $F$. Leishmaniasis cutanea diseminada anergica. Med Cut ILA 1966:3:287-292.

16. Nery-Guimarães F. Estado atual dos conhecimentos da forma lepromatóide da leishmaniose tegumentar. Hospital 1965;67:57-76.

17. Portugal $\mathrm{H}$, Marques A. Leishmaniose tegumentar difusa. Hospital $1960 ; 57: 11-21$.

18. Rodriguez G, Conedor A, Caceres E, Cassiano G. Arroyo C, Palan MT, Boshell J. Leishmaniasis difusa. Biomédica 1985:5:95-111.

19. Silva AR, Mendes J, Rodrigues M, Carvalho ZS, Reis FM, Melo JE, Morais JC. Leishmaniose cutânea difusa (LCD). Registro de um caso cm Buriticupu, Estado do Maranhão-Brasil. Rev Inst Med Trop São Paulo 1981;23:31-35.

20. Silva D, Maroja R, Salgado U, Lourciro A. Leishmaniose anérgica hansenóide. Dermatol Iber Latin Am 1972;4:493-505.

21. Simpson M, Mullins J, Stone O. Disseminated anergic cutancous leishmaniasis. Arch Dermatol 1968:97: 301-303.

22. Zerega F. Sobre um caso de leishmaniasis tegumentaria difusa. Rev Ecuat Hig Med Trop 1961:18:18-20.

23. Takahashi S, Sato T. Disseminierte kutane leishmaniose. Hautarzt 1981:32:459-462.

24. Velasco O. Savarino S, Walton G, Gam A, Neva F. Diffuse cutaneous leishmaniasis in Mexico. Am J Trop Med Hyg 1989:41:280-288.

25. Titus RG, Sherry B, Cerami A. Tumor necrosis factor plays a protective role in experimental murine cutaneous leishmaniasis. J Exp Med 1989:6:2097-2104.

26. Barral-Netto M, Barral A, Brownell CE, Skeiky YAW, Ellingsworth LK, Twardzik DR, Reed SG. Transforming growth factor- $\beta$ in leishmanial infection: a parasite escape mechanism. Science 1992:257: 545-548.

27. Barral A, Barral-Netto M, Yong EC, Bronell CE, Twardzik DR, Reed SG. Transforming growth factor- $\beta$ as a virulence mechanism for Leishmania braziliensis. Proc Natl Acad Sci USA 1993;90:34423446.

28. Ding A, Nathan CF. Graycar J, Derynck R, Stuehr DJ, Srimal S. Macrophage deactivating factor and transforming growth factors-beta 1, -beta2, and -beta3 inhibit induction of macrophage nitrogen oxide synthesis by IFN-gamma. J Immunol 1990;145:940-944.

29. Moll H, Fuchs $H$, Blank C, Röllinghoff $M$. Langerhans cells transport Leishmania major from the infected skin to the draining lymph node for presentation to antigen-specific T cells. Eur J Immunol 1993; 23:1595-1601.

30. Cucé LC, Belda W Jr, Zolli CA. Leishmaniose tegumentar na infância. An Bras Dermatol 1990;65:185195.

31. Griffiths WAD. Old World cutaneous leishmaniasis. In: Peters W, Killick-Kendrick R, eds. The leishmaniasis in biology and medicine. Clinical aspects and control. Vol. II. London: Academic Press, 1987:618636.

32. Bittencourt AL, Costa JML, Carvalho EM, Barral A. Leishmaniasis recidiva cutis in American cutaneous leishmaniasis. Int J Dermatol 1993:32:802-805.

33. Carvalho EM, Barral A, Costa JML, Bittencourt AL, Marsden P. Clinical and immunological aspects in disseminated cutaneous leishmaniasis. Acta Tropica 1994;56:315-325.

34. Kubba R, El Hassan AM, Al Gindan Y, Omer AHS, Kutty MK, Saeed MB. Dissemination in cutancous leishmaniasis. I. Subcutaneous nodules. Int J Dermatol 1987;26:300-304.

35. Barral A, Guerreiro J, Bonfim G, Correia D, BarralNetto M. Carvalho EM. Lymphadenopathy as the first sign of human cutaneous infectioin by Leishmania braziliensis. Am J Trop Med Hyg 1995;53:256259.

36. Al-Gindan Y, Kubba R, El Hassan EM, Omer AHS, Kutty MK, Saeed MB. Dissemination in cutaneous leishmaniasis. 3. Lymph node enlargement. Int $\mathbf{J}$ Dermatol 1989:28:248-254.

37. Morierty PL, Bittencourt AL, Pereira $C$, et al. Borderline cutaneous leishmaniasis. Clinical, immunological and histological differences from mucocutaneous leishmaniasis. Rev Inst Med Trop São Paulo 1978;20:15-21

38. Barral A. Costa JML, Bittencourt AL, Barral-Netto M. Carvalho EM. Polar and subpolar diffuse cutaneous leishmaniasis in Brasil: clinical and immunopathological aspects. Int J Dermatol 1995:34:474 479.

39. Rees PH, Kager PA. Visceral leishmaniasis and postkala-azar dermal leishmaniasis. In: Peters W. KillickKendrick R, eds. The leishmaniases in biology and medicine. Vol. Il. London: Academic Press, 1987:584-596.

40. Carvalho EM. Johnson WD, Barreto E, Marsden PD, Costa JLM, Reed S. Rocha H. Cell mediated immunity in American cutancous and mucoculaneous leishmaniasis. J Immunol 1985;135:4144-4148.

41. Ridley DS. Ridley MJ. The evolution of the lesion in cutancous leishmaniasis. J Pathol 1983:141:83-96.

42. Bitiencourt AL, Barral A. Evaluation of the histopathological classifications of American cutaneous and mucocutaneous leishmaniasis. Mcm Inst Oswaldo Cruz 1991;86:51-56.

43. Ghalib HW. Eltoum EA, Kroon CCM, El Hassan AM. Identification of Leishmania from mucosal leishmaniasis by recombinant DNA probes. Trans $R$ Soc Trop Med Hyg 1992;86:158-160.

44. Lopez $M$, Inga $R$, Cangalaya $M$, Echevarria $J$, Llanos-Cuentas A, Orrego C, Arevalo J. Diagnosis of Leishmania using the polymerase chain reaction: a simplified procedure for field work. Am J Trop Med Hyg 1993;43:348-356.

45. Bittencourt A, Barral A, Jesus A, Almeida RP, Grimaldi $\mathrm{G} \mathrm{J}_{\mathrm{r}}$. In situ identification of Leishmania amazonensis associated with diffuse cutancous leishmaniasis in Bahia, Brazil. Mem Inst Oswaldo Cruz 1989; 84:585-586.

46. Barral-Netto M, Machado P, Barral A, Human cutaneous leishmaniasis: recent advances in physiopa- 
thology and treatment. Eur J Dermatol 1995;5:104113.

47. Marsden PD. Mucosal leishmaniasis due to Leishmania (vianna) braziliensis $\mathrm{L}(v) \mathrm{b}$ in Três Braços. BahiaBrazil Rev Soc Bras Med Trop 1994;27:93-101.

48. Costa JML, Saldanha ACR, Silva ACM, Serra Neto A. Galvāo CES, Pedroso e Silva AR. Estado atual da leishmaniose cutânea difusa (LCD) no estado do Maranhão. II. Aspectos epidemiológicos, clínicosevolutivos. Rev Soc Bras Med Trop 1992;25:115-123.

49. Soto-Mancipe J, Grogl M, Berman JD. Evaluation of pentamidine for the treatment of cutaneous leishmaniasis in Colombia. Clin Infect Dis 1993;16:417-425.

50. Costa JML, Sampaio RN, Tada MS, Almeida EA. Veiga EP. Magalhāes AV. Marsuen PD. Furazolidone treatment of cutaneous leishmaniasis. Trans $R$ Soc Trop Med Hyg 1985;79:274.

51. Barrios LA, Costa JML, Netto EM. Vexenat A. Cuba Cuba CA, Marsden PD. Intralesional glucantime in Leishmania braziliensis braziliensis infections. Trans R Soc Trop Med Hyg 1986;80: 173-174.

52. Kellum RE. Treatment of cutaneous leishmaniasis with an intralesional antimonial drug (Pentostam). J Am Acad Dermatol 1986;15:620-622.

53. Krause G. Kroeger A. Topical treatment of American cutaneous leishmaniasis with paramomycin and methylbenzethonium chloride: a clinical study under field conditions in Ecuador. Trans R Soc Trop Med Hyg 1994;88:92-94.

54. El-On J, Weinrauch L, Livshin R, Even-Paz Z, Jacobs GP. Topical treatment of recurrent cutaneous leishmaniasis with ointment containing paramomycin and methylbenzethonium chloride. Brit Med J 1985; 291:704-705.

55. Asilian A, Jalayer T, Whiteworth JAG, Ghasemi RL, Nilforooshzadeh $M$. Olliaro $P$. A randomized, placebo-controlled trial of a two-week regimen of aminosidine (paramomycin) ointment for treatment of cutaneous leishmaniasis in Iran. Am J Trop Med Hyg 1995;53:648-651.

56. Costa JML, Barrios LA, Netto EM, Marsden PD. Topical Pentostam in attempt to produce more rapid healing of skin ulcers due to Leishmania braziliensis braziliensis ulcers. Rev Soc Bras Med Trop 1986;19: 199-200.

57. Moray TA, Abedel-Rahman EG, Ahmed AM. Treatment of cutaneous leishmaniasis with Pentostam or cryosurgery. J Egypt Soc Parasit 1989;19:533-534.

58. Bittencourt AL, Badaró R, Costa J, Barral A, Badaró $F$, Carvalho EM. Effect of pentavalent antimonial and IFN- $\gamma$ treatment on the histopathological and ultrastructural aspects of diffuse cutaneous leishmaniasis due to Leishmania amazonensis. Eur J Dermatol 1996:6(4)264-267. 
This document is a scanned copy of a printed document. No warranty is given about the accuracy of the copy. Users should refer to the original published version of the material. 